\title{
KONSEP DIRI REMAJA DITINJAU DARI LATAR BELAKANG BUDAYA MANDAILING DAN BUDAYA MINANGKABAU SERTA IMPLIKASINYA DALAM BIMBINGAN DAN KONSELING
}

\author{
Sukatno 1),Vitria Larseman Dela 2), Anas Munandar 3) \\ Dosen Bimbingan dan Konseling Universitas Muhammadiyah \\ Tapanuli Selatan (UMTS)
}

Email: Sukatno@um-tapsel.ac.id

\begin{abstract}
ABSTRAK
Budaya, merupakan bagian tak terpisahkan dari diri manusia sehingga banyak orang cenderung menganggapnya diwariskan secara genetis. Indonesia memiliki banyak keberagaman budaya, salah satunya adalah kebudayaan yang berkembang dikalangan remaja. Jenis penelitian yang digunakan adalah metode kualitatif artinya penelitian dilakukan secara mendalam serta menggunakan pendekatan deskriptif yang bermaksud untuk mendapatkan gambaran tentang konsep diri remaja pada budaya mandailing dan budaya minangkabau. Hasil penelitian adalah Orang Minang berpandangan bahwa hidup pada hakikatnya baik, karena itu tujuan hidup adalah berbuat kebaikan atau jasa, "hiduik bajaso, mati bapusako", mereka ibaratkan: gajah mati maninggakan gadiang, harimau mati maninggkan baling, manudia mati maninggakan namo". Pepatah itu mengisyaratkan bahwa hidup adalah menghasilkan, setiap orang harus bekerja dan produktif sewaktu ia hidup sehingga dapat meninggalkan sesuatu apabila telah meninggal. Sebagai individu orang Minang sangat egaliter, hal itu dinyatakan dalam ungkapan "duduk samo randah tagak samo tinggi. Ungkapan ini membuka kesempatan kepada setiap individu untuk mencari yang terbaik, karena setiap orang itu pada prinsipnya menpunyai hak yang sama dalam berinisiatif dan memutuskan sesuatu. Masyarakat mandailing dikenal sebagai masyarakat yang memiliki sosial yang tinggi. Hal ini dapat dibuktikan dengan meninjau partisipasi masyarakat dalam menghadiri berbagai acara dan peristiwa yang terjadi di daerah pemukiman sukunya seperti menghadiri takjiah, mengadakan pengajian, menghadiri kemalangan (melayat), mengunjungi orang yang sedang sakit, dan sebagainya. Saran terhadap penelitian ini, penelitian ini akan lebih baik jika dikembangkan lagi secara mendalam mengenai dua latar belakang budaya yang sangat berbeda. Baik ditinjau dari sifat, karakteristik, adat-istiadat, suku dan kebiasaan hidup.

Kata kunci : Budaya ; sosial ; pendekatan deskriptif
\end{abstract}

\begin{abstract}
Culture, is an inseparable part of human beings so that many people tend to think of it as being genetically inherited. Indonesia has many cultural diversity, one of which is a culture that develops among teenagers. The type of research used is a qualitative method, meaning that the research is carried out in depth and uses a descriptive approach that intends to get an idea of the self-concept of adolescents in the mandailing culture and Minangkabau culture. The results of the study were that the Minang people were of the view that life was essentially good, therefore the purpose of life was to do good or service, "hiduik bajaso, dead bakoako", they likened: elephants died raising their faces, tigers died out propellers, and they died namo ". The saying implies that life is to produce, everyone must work and be productive when he lives so that he can leave something when he dies. As an individual Minang is very egalitarian, it is stated in the phrase "sitting samo randah tagak samo high. This expression opens the opportunity for each individual to look for the best, because each person in principle has the same rights in initiating and deciding something. Mandailing communities are known as people who have high social status. This can be proven by reviewing community participation in attending various events and events that occur in the tribal residential areas such as attending takjiah, holding recitals, attending misfortune (mourning), visiting sick people, and so on. Suggestions for this research, this research would be better if it was further developed in two very different cultural backgrounds. Good in terms of nature, characteristics, customs, tribes and life habits.
\end{abstract}

Keywords: Culture; social; descriptive approach 


\section{PENDAHULUAN}

Budaya adalah suatu cara hidup yang berkembang dan dimiliki bersama oleh sebuah kelompok orang dan diwariskan dari generasi ke generasi. Dalam proses sosial kebudayaan tidak pernah lepas dari konsep diri. Gagasan tingkah laku, atau tindakan manusia itu di tata, dikendalikan pola-polanya oleh sistem nilai dan norma dalam masyarakat. Sebaliknya, kebudayaan turut memberikan sumbangan pada pembentukan konsep diri seseorang. Walaupun berbeda satu sama lain hal itu akan dirancang oleh norma dalam proses sosialisasi dan proses kebudayaan selama hidup sejak masa kecil. Ciri-ciri dan unsur-unsur konsep diri sudah tertanam dalam jiwa seseorang sejak awal, yaitu di masa kanak-kanak melalui proses sosialisasi dalam keluarga yang tentunya akan di pengaruhi oleh faktor daerah, cara hidup di desa atau kota, agama, kelas sosial, dan sebagainya.

Sebagian besar konsep diri banyak di pengaruhi dalam masa kanak-kanak hal itu ditentukan dengan bagaimana ia makan, bermain,berbicara,disiplin dan bergaul dengan anak-anak lain. Setelah anak itu dewasa, 1 beberapa watak yang sama akan tampak menonjol pada banyak individu yang menjadi dewasa itu. Konsep diri akan mengacu pada ciri khas dan sifat seseorang, termasuk2. dalam konsepnya mewakili pola-pola pemikiran, perasaan, dan segala kebiasaan lainnya. Individu dan perilakunya tentunya akan di sesuaikan dengan masyarakat, lingkungan dan kebudayaan itu sendiri. Budaya, merupakan bagian tak terpisahkan dari diri manusia sehingga banyak orang cenderung menganggapnya diwariskan secara genetis. Indonesia memiliki banyak keberagaman budaya, salah satunya adalah kebudayaan yang berkembang dikalangan remaja. Kebudayaan remaja Indonesia kental dengan perilakunya yang sopan, santun, ramah dan saling menghargai, sehingga dapat pula saling menjalin tali persaudaraan. Hal seperti itulah yang harus di jaga bahkan di lestarikan, karena itu juga merupakan salah satu ciri dari kebudayaan yang berkembang di Indonesia.

Konsep tentang diri ada hubungannya dengan budaya dan dengan adanya budaya yang berbeda-beda, hal itu telah menyumbang terciptanya konsep diri yang berbeda-beda pula. Budaya dengan ciri individualistik umumnya memiliki konsep diri yang independent, sementara yang berbudaya kolektif memiliki konsep diri yang interdependent. Perbedaan konsep diri ini membawa pengaruh pada banyak aspek lain perilaku seseorang. Berkaitan dengan hubungan antara budaya dan kepribadian, terdapat perbedaan pandangan.

Berbagai budaya yang ada di Indonesia, padab) pulau sumatera ada terdapat banyak ragam budaya. Salah satunya adalah budaya mandailing dan budaya minangkabau. Dua budaya ini sungguh memiliki perbedaan yang sangat mencolok, dimana budaya mandailing mengikuti keturunan dari garis keturunan bapak atau disebut juga aliran patrilineal. Pada budaya minangkabau mengikuti garis keturunan ibu atau disebut juga aliran Matrilineal. Perbedaan yang mencolok dari dua budaya ini akan berpengaruh terhadap pandangan,a) kepribadian, persepsi dan konsep diri yang tertanam pada masyarakatnya. Konsep diri seseorang juga dipengaruhi oleh adat istiadat, budaya, aturan dan norma yang berlaku di daerah tersebut. Konsep diri masyarakat mandailing akan berbeda dengan konsep diri masyarakat minangkabau karena memiliki perbedaan yang mencolok jika dilihat dari garis keturunan yang bersifat patrilineal dan Matrilineal.

\section{METODE PENELITIAN}

Jenis penelitian yang digunakan adalah metode kualitatif artinya penelitian dilakukan secara mendalam serta menggunakan pendekatan deskriptif yang bermaksud untuk mendapatkan gambaran tentang konsep diri remaja pada budaya mandailing dan budaya minangkabau. Penelitian ini difokuskan di dua kota yaitu kota padangsidimpuan tepatnya di Batang Angkola (remaja mandailing) dan kota padang (remaja minangkabau) tepatnya di kelurahan Balai Gadang. Alasan memilih lokasi penelitian ini, sebagai berikut:

Kota Padangsidimpuan yaitu tepatnya di Batang Angkola terdapat banyak masyarakat dan remaja yang memiliki keturunan Mandailing.

Kota Padang yaitu tepatnya di kelurahan Balai Gadang terdapat masyarakat dan remaja yang asli keturunan Minangkabau dan masih memegang teguh nilai-nilai adat istiadat yang berlaku pada budaya Minangkabau.

Informan penelitian ini adalah remaja yang berumur antara 13-20 tahun yang berasal dari keturunan Mandailing yang tinggal di daerah batang Angkola. Informan selanjutnya yang berasal dari budaya Minangkabau adalah remaja yang berumur 13-20 tahun yang tinggal di kelurahan Balai Gadang. Informan yang berasal dari budaya Mandailing yaitu remaja yang ada dalam kegiatan Naposo Nauli Bulung sedangkan informan yang berasal dari budaya Minangkabau yaitu remaja masjid atau mushalla yang ada di kelurahan Balai Gadang yang aktif mengikuti kegiatan adat istiadat dan kegiatan lainnya. Jumlah masing-masing informan primer dalam penelitian ini adalah 5 orang. Jadi jumlah total informan dalam penelitian ini adalah 10 orang. Untuk informan tambahan peneliti memilih tokoh-tokoh adat, ketua pemuda/remaja, dan pemuka masyarakat di masingmasing budaya atau daerah tempat penelitian dilakukan.

Teknik pengumpulan data yang peneliti gunakan disini yaitu:

\section{Data Primer}

Observasi

Dalam hal ini penelitian melakukan pengamatan secara langsung untuk memperoleh data yang sekiranya mendukung dan melengkapi materi atau data yang diperoleh dari wawancara yang dilakukan dari para responden (Sukardi, 2003:24). Peneliti melakukan pengamatan langsung kelapangan sesuai dengan objek yang telah peneliti tetapkan yaitu konsep diri remaja, kepribadian yang ditampilkan dan persepsi remaja yang berbeda budaya yaitu Mandailing dan Minangkabau.

Wawancara Mendalam 
Sesuai dengan dasar penelitian yang dilaksanakan yaitu studi kasus, maka cara pengumpulan data dengan cara wawancara sangat tepat sebab dimungkinkan untuk memperoleh informasi lebih detail dari objek yang diteliti. Data yang diperoleh terdiri dari kutipan langsung dari responden mengenai pengalaman, pendapat, perasaan dan pengetahuannya terhadap subjek yang diteliti. Wawancara ini penulis lakukan dengan menggunakan teknik snowball ( Bagong Suyanto, 2011: 186).

2.Data Skunder

Data ini diperoleh dari studi kepustakaan. Studi kepustakaan dimaksud untuk memperoleh teori, konsep maupun keterangan-keterangan melalui hasil penelitian, buku-buku, skripsi, tesis, jurnal, majalah, atau bahanbahan yang berkaitan dengan masalah yang diteliti. Hasil penelitian tersebut yang kemudian dianalisis secara deskriptif (Iskandar, 2009: 252).

Sesuai dengan penelitian ini, maka data yang ada dianalisis dengan teknik kualitatif deskriptif, artinya datadata yang ada dianalisis di lapangan dikumpulkan kemudian diolah dengan klasifikasi dan dianalisis secara kualitatif dengan berpedoman pada kerangka pikiran yang telah disajikan guna memberikan gambaran yang jelas dari masalah yang diteliti (Iskandar, 2009: 221).

\section{Alur Pelaksanaan Penelitian}
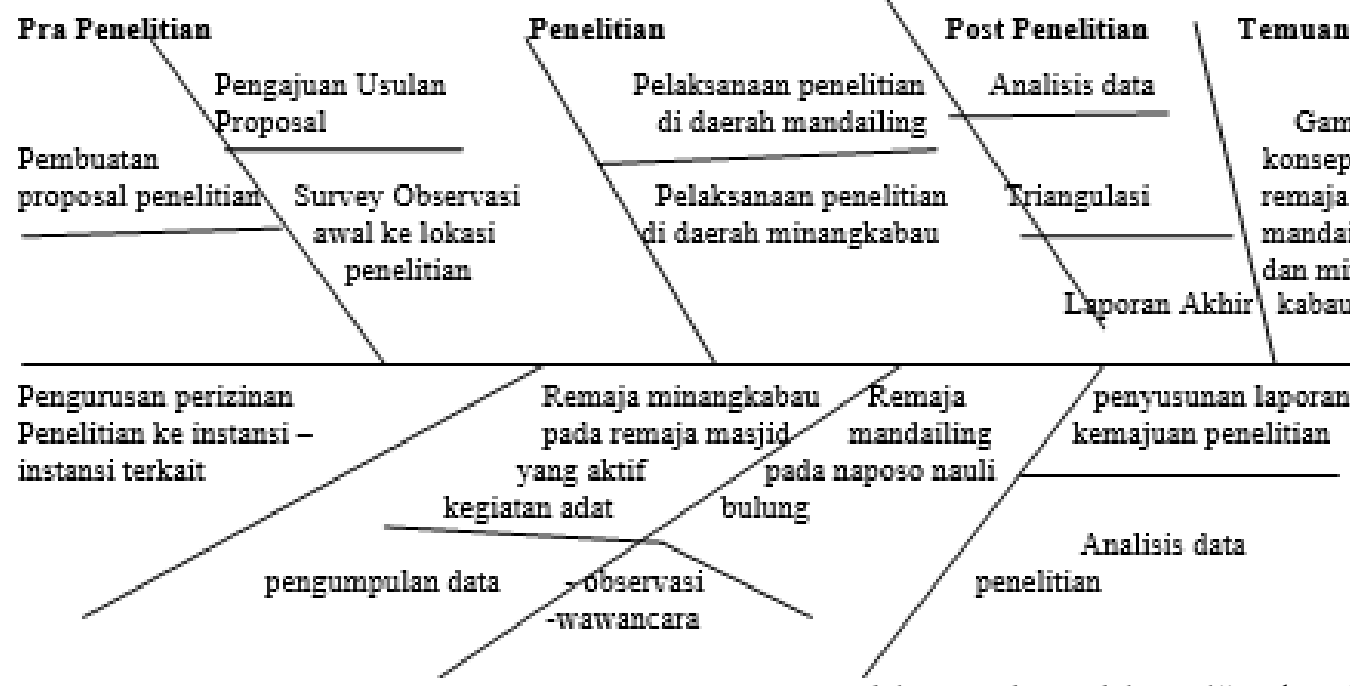

dek urang baitu dek awak", sebagaimana orang lain dapat berhasil begitu juga kita sebagai pribadi. Motivasi untuk berprestasi dan meraih kedudukan yang sama dengan orang lain adalah faktor yang akan menentukan nilai dan harga diri seorang Minang.

Sistem matrilinial pada sisi lain meletakkan laki-

\section{HASIL DAN PEMBAHASAN}

\section{A. Konsep Diri Remaja Pada Budaya Minangkabau}

Berdasarkan hasil wawancara dengan Bapak Eri pada tanggal 03 Juli 2018 selaku pemuka adat minangkabau mengatakan bahwa "melihat orang Minang" adalah melihat nilai yang mereka anut sebagai falsafah hidupnya, yaitu sistem nilai budaya dan adat istiadat yang berfungsi sebagai pedoman dan pendorong setiap perilaku dari individu Minang itu sendiri. Sistem nilai itu yang akan memberikan arah atau orientasi kepada setiap orang Minang. Falsafah adat Minangkabau tradisional segalanya bersumberkan pada alam, Alam Takambang Jadi Guru. Alam beserta hukum dan fenomenanya juga gejala-gejala yang ada dibaliknya dipedomani dan dipahami dalam memaknai arti hidup dan kehidupan. Alam selalu berubah berevolusi menuju kepada kesempurnaan dengan tetap berdasarkan pada hukum-hukumnya, begitu juga harusnya individu berorientasi pada kesempurnaan dengan mengembangkan kreatifitas.

Orang Minang berpandangan bahwa hidup pada hakikatnya baik, karena itu tujuan hidup adalah berbuat kebaikan atau jasa, "hiduik bajaso, mati bapusako", mereka ibaratkan: gajah mati maninggakan gadiang, harimau mati maninggkan baling, manudia mati maninggakan namo".Pepatah itu mengisyaratkan bahwa hidup adalah menghasilkan, setiap orang harus bekerja dan produktif sewaktu ia hidup sehingga dapat meninggalkan sesuatu apabila telah meninggal. Sebagai individu orang Minang sangat egaliter, hal itu dinyatakan dalam ungkapan "duduk samo randah tagak samo tinggi. Ungkapan ini membuka kesempatan kepada setiap individu untuk mencari yang terbaik, karena setiap orang itu pada prinsipnya menpunyai hak yang sama dalam berinisiatif dan memutuskan sesuatu. Keinginan untuk sama dengan orang lain selalu digambarkan dengan " $b a a$ 
sesuku dan sekampung, ia juga dituntut untuk bertanggung jawab pada istri dan anak-anak serta seluruh keturunannya.

Prisip dasar nilai normatif dari sistem matrilinial adalah adalah berorientasikan pada beberapa aspek diantaranya :

a) Remaja laki-laki untuk lebih mandiri, baik dalam bentuk financial maupun dalam bentuk personality.

b) Nilai tanggung jawab kaum laki-laki terhadap keluarganya.

c) Nilai perlindungan terhadap kaum perempuan, baik perlindungan dalam bentuk moral maupun dalam bentuk material.

d) Nilai komunalistik yaitu ikatan kekerabatan dalam masyarakat Minangkabau.

e) Harga diri, yang melahirkan aktivitas dan kreatifitas untuk berprestasi.

f) Raso pareso (Rasa, periksa) yang melahirkan sikap positif dan objektif, penuh perhitungan dan pertimbangan yang matang dalam berbuat dan melakukan sesuatu.

g) Rasa "malu" dan "hina" jika harga dirinya jatuh karena melakukan hal yang bertentangan dengan nilai-nilai dan norma adat yang ada dalam masyarakat aspek ini melahirkan sikap terikat pada tuntutan adat.

Kata perempuan dan bundo kanduang pada budaya minangkabau bermakna umum dan acuannya luas, sedangkan frasa "bundo kanduang" mengacu kepada sosok perempuan yang punya sifat dan kepribadian yang (1) memahami adat dan sopan santun,(2) mengutamakan budi pekerti, (3) memelihara harga diri, (4) mengerti agama, (5) memahami aturan agama, (6) memelihara dirinya dan masyarakatnya dari dosa. Adat Minangkabau pada khususnya membentuk individu dan perempuan yang berbudi luhur, manusia yang berbudaya, manusia yang beradab. Sifat-sifat ideal itu adalah (a) Hiduik baraka, baukua jo bajangko, artinya orang minang harus mempunyai "rencana yang jelas dan perkiraan yang tepat"; (b) baso-basi malu jo sopan, artinya adat Minang mengutamakan sopan santun dalam pergaulan; (c) tenggang raso, artinya di dalam pergaulan yang baik kita harus menjaga perasaan orang lain. Dalam pergaulan, adat mengajarkan kita selalu berhati-hati dalam berbicara, bertingkah laku tidak menyinggung perasaan orang lain; (d) setia., artinya teguh hati, merasa senasib dan menyatu dalam lingkungan kekerabatan.

\section{B. Konsep Diri Remaja Pada Budaya Mandailing}

Masyarakat mandailing dikenal sebagai masyarakat yang memiliki sosial yang tinggi. Sebagai masyarakat mayoritas penganut agama islam suku ini memandang kekerabatan sesama saudara seiman amatlah penting, Hal ini dapat dibuktikan dengan meninjau partisipasi masyarakat dalam menghadiri berbagai acara dan peristiwa yang terjadi di daerah pemukiman sukunya seperti menghadiri takjiah, mengadakan pengajian, menghadiri kemalangan(melayat), mengunjungi orang yang sedang sakit, dan sebagainya. Berdasarkan hasil wawancara dengan salah satu
remaja yaitu GN mengatakan bahwa "remaja Mandailing biasanya berani berkelahi di luar daerahnya walaupun sedang sendiri. Tidak suka mengeroyok kecuali dalam keadaan terpaksa. Orang Mandailing hampir 100 percen beragama Islam dan termasuk penganut agama yang cukup taat. Remaja Mandailing sangat menghormati perbedaan. Buktinya tidak pernah terjadi perkelahian antar agama di Tanah Mandailing. Banyak yang saya puji dalam sifat sifat orang Mandailing. Orang Mandailing tidak suka mencuri. Buktinya jarang terjadi perampokan, pencurian maupun penodongan di daerah Mandailing. Berdasarkan hasil observasi bandingkan di beberapa daerah di luar Mandailing, bila ada truck jatuh, maka orang orang setempat akan menjarah muatan truck itu. Penduduk Mandailing tidak mau menjarah orang yang kecelakaan. Dalam dunia dagang, orang Mandailing juga sangat pandai dan pintar. Banyak daerah pasar di kota lain yang telah dikuasai pendatang China. Baik di daerah kecamatan maupun di kabupaten. Tapi di daerah Mandailing, sektor ekonomi benar benar dikuasai penduduk asli Mandailing.

\section{KESIMPULAN}

Pembentukan karakteristik individu Minang selain didasarkan pada sistem nilai budaya yang ada, juga dapat dipengaruhi oleh sistem sosiolkultural yang berkembang dalam masyarakat. Adat matrilinial salah satu contoh hal yang juga berperan dalam pembentukan kepribadian terutama individu laki-laki Minangkabau. Dari karakter umum dari suku Mandailing, kita dapat mengambil beberapa nilai yang tergantung didalamnya seperti peranan agama dalam hidup bermasyarakat merupakan gambaran sistem sosial yang terdapat disuatu daerah, kemudian pentingnya nilai kesopanan dan kesantunan dalam hidup bermasyarakat merupakan kunci keharmonisan masyarakat dalam suatu daerah,

\section{SARAN}

Saran terhadap penelitian ini, penelitian ini akan lebih baik jika dikembangkan lagi secara mendalam mengenai dua latar belakang budaya yang sangat berbeda. Baik ditinjau dari sifat, karakteristik, adat-istiadat, suku dan kebiasaan hidup. Peneliti berharap agar hasil dari penelitian ini dapat diterima di jurnal-jurnal nasional terakreditasi karna merupakan penelitian sosial yang berlintas budaya konseling. Sehingga sangat membantu dalam kegiatan konseling lintas budaya.

\section{Daftar Pustaka}

dur-Razzaq Lubis. Mandailing-Batak-Malay: A People Defined and Divided. In: 'From Palermo to Penang: A Journey into Political Anthropology', University of Fribourg, 2010

Afifudin. 2012. Metodologi Penelitian Kualitatif. Bandung : Pustaka Setia

gustiani, Hendriati. 2006. Psikologi Perkembangan: Pendekatan Ekologi Kaitannya dengan Konsep Diri dan 
Penyesuaian Diri pada Remaja. Bandung: PT Refika Aditama.

PT Refika Aditama.

2009. Psikologi Perkembangan. Bandung:

Bagong Suyanto. 2011. Metode Penelitian Sosial. Jakarta: Kencana Prenada Media Group

Chadwick, R.J. 1991, "Matrilinial Inheritance and Migration in a Minangkabau Community". Journal Manuscripts to Indonesia. Cornell Modern Indonesia Project., the Chicago Maual of style., ed 13, no 51, hlm 47-81.Society (MBRAS), 2003.

Hurlock, Elizabeth B. 2010. Perkembangan Anak. Edisi Keenam: Jilid 2. (Alih bahasa: Med. Meitasari Tjandrasa). Jakarta: Erlangga.

Iskandar. 2009. Metodologi Penelitian Pendidikan dan Sosial (Kuantitatif dan Kualitatif). Jakarta : Gaung Persada Press

Murmanto, Melanie D. 2007. Pembentukan Konsep Diri Siswa melalui Pembelajaran Partisipatif (Sebuah Alternatif Pendekatan Pembelajaran di Sekolah Dasar). Jurnal Pendidikan Penabur (No.08/Th.VI). Hlm. 66-74.

Sukardi. 2003. Metodologi Penelitian Pendidikan. Yogyakarta: Bumi Aksara

Yudit Oktaria Kristiani Pardede. 2008. Konsep Diri Anak Jalanan Usia Remaja. Jurnal Psikologi (Volume 1, No.2). Hlm. 146-151

Yunus., 2001. Kebudayaan Minangkabau., dalam Manusia dan Kebudayaan di Indonesia. Djambatan. Jakarta. 